\title{
Biography and Form of Life Toward a Cultural Analysis of Narrative Interviews ${ }^{1}$
}

\author{
Werner Binder ${ }^{2}$ - Dmitry Kurakin ${ }^{3}$ \\ Faculty of Social Studies, Masaryk University. Brno \\ National Research University Higher School of Economics, Moscow
}

\begin{abstract}
Biography and Form of Life. Toward a Cultural Analysis of Narrative Interviews. This paper introduces the concept of form of life, socially shaped and shared meaning structures of actors situated in material contexts, as a tool for the cultural-sociological analysis of biographies and life trajectories. Following the principles of structural hermeneutics, such an analysis of life-forms treats the interview text as manifestation of a deeper holistic meaning structure, embodied in narratives, binaries and metaphors, without suppressing the contradictions and tensions inherent in every form of life. Finally, the empirical applicability of our approach is illustrated with examples from the qualitative strand of a broader longitudinal panel study as well as an in-depth case study.

Sociológia 2019, Vol. 51 (No. 6: 563-583)

https://doi.org/10.31577/sociologia.2019.51.6.23
\end{abstract}

Key words: Cultural sociology; form of life; narrative interviews; biography; structural hermeneutics

"Geprägte Form, die lebend sich entwickelt" (The minted form that lives and living grows)

Goethe, Urworte Orphisch

The aim of our paper is to introduce the concept of "form of life" into interpretative sociology, particularly in the context of the recent cultural sociological debate on narrative interviews (Pugh 2013; 2014; Vaisey 2014). We argue that forms of life can be turned into a powerful tool for the cultural analysis of biographies and life trajectories. After introducing the concept in the context of theoretical debates on culture and sketching a suitable methodological tool-kit, we will demonstrate our approach with the analysis of narrative interviews that were conducted as part of the Russian panel study Trajectories in Education and Career (Kurakin 2014b).

Our endeavor is rooted in the field of cultural sociology, which applies methods of cultural analysis to social phenomena. More specifically, we are committed to a "strong program" in cultural sociology highlighting the analytical autonomy and causal efficacy of culture (Alexander - Smith 2001). We

\footnotetext{
1 Funding: Results of the project Trajectories in Education and Career, carried out within the framework of the Basic Research Program at the National Research University Higher School of Economics (HSE), are presented in this work. Both authors have contributed equally to the article.

2 Address: Dr. Werner Binder, Faculty of Social Studies, Masaryk University. Joštova 10, 60200 Brno, Czech Republic. Email: werner.binder@muni.cz

3 Address: Dr. Dmitry Kurakin, National Research University Higher School of Economics, Potapovskiy pereulok 16 building 10, office 407, 101000 Moscow, Russia. E-mail: dmitry.kurakin@hse.ru
} 
argue that the empirical research of life trajectories has to take culture seriously, because shared meaning structures shape beliefs, aspirations and life choices of actors. Instead of reducing culture to formal properties such as a "cultural capital", which actors accumulate and use strategically in their life course (e.g. Bourdieu 1984), we treat cultures substantively, as "whole ways of life" (Williams 1960). To understand how culture affects life trajectories, one should reconstruct cultural wholes from within, instead of just treating culture as a resource for vertical mobility.

Furthermore, we are convinced that the apparent heterogeneousness found within life stories can only be a starting point for the theorization of biographies, not the final assertion of an inconsistent nature of culture. Wittgenstein's conception of "form of life" (2009; cf. Derra 2007), we belief, is apt to grasp the unity and integrity of cultural patterns of life trajectories. In contrast to phenomenological approaches to biography or ethnomethodological accounts on accounts, we believe that the source of this integrity and unity is situated at a cultural-structural level. Forms of life as deep meaning structures can be analyzed by means of structural hermeneutics, a methodological framework which we will discuss after our theoretical exposition.

\section{Dataset, samples and cases: Collection, selection and interpretation}

Introducing the concept of form of life, we use empirical examples and a case study from a set of interviews collected as part of the longitudinal study "Trajectories in Education and Career" carried out at the Higher School of Economics in Moscow since 2009. The survey focuses on educational and occupational choices of young people in Russia and includes information on more than twenty-five thousand respondents across several panels. Since 2012, narrative interviews with roughly $1 \%$ of the participants of several panels, divided into thematic subpanels, are conducted in addition to the surveys in order to complement the quantitative data ${ }^{4}$. The interviews covered the biographies of the respondents devoting special attention to their educational and occupational choices. Furthermore, questions relevant for the thematic

\footnotetext{
${ }^{4}$ For the purpose of our current research project, we use one of these subpanels as the main sample, and two more as subsidiary samples. The main sample consists of 38 interviews: twenty-five interviews were conducted in 2012 and thirteen as follow-up interviews with the same respondents in 2014. It was selected for three reasons. First of all, it contains the oldest respondents of the study, who were at its beginning in 2009/2010 senior undergraduates at different universities in two regions in Russia. By the time of their first interview, the respondents were approximately 25 years old; they had entered already the labor market and were relatively settled in terms of lifestyle. Secondly, the main sample was at that time the only subpanel where we conducted two waves of qualitative interviews, which gave it a longitudinal dimension. Last but not least, the interviews covered the general topics of educational and professional choice, whereas a second subpanel of the same age, which we selected as subsidiary sample ( 25 cases), focused on the more specific theme of reconciling maternity and career. The second subsidiary sample (40 cases) represents a younger cohort, high school students in a metropolis who were nominated by their peers as gifted. In the following, we will mainly work with interviews from the main sample, from which also our case study was selected, but we will use examples from the subsidiary samples for the purpose of illustrating our theoretical arguments and methodological tools.
} 
topic of the respective subpanel (as well as questions related to previous interviews) were asked.

A small number of interviews - including the case study in this article were selected for their richness, translated from Russian into English and interpreted in a group of five researchers (including the original interviewers). We used the English translations as basis for the discussion but frequently consulted the Russian originals to resolve ambiguities and disputes about the wording. We started the interpretation of each case with passages that we found particularly rich or puzzling, proceeded then in our analysis sequentially, aiming for a comprehensive case structure, which could then be tested and modified in light of other passages. Other interviews, including the follow upinterview with the respondent of our case study, were only interpreted by the authors of this article.

\section{Theoretical framework: Life-form as formula of integrity of life trajecto- ries}

In this section, we introduce "forms of life" as a theoretical tool for the cultural analysis of biographies and life trajectories through narrative interviews. Our proposal is based on the assumption that typical and collectively developed life trajectories, shaped by cultural patterns, exist. For this reason we need to be able to conceptualize the unity and integrity of biographies and cultures without ignoring their dynamism and complexity. The Wittgensteinian notion of "form of life" seems best suited for this task. We will discuss the term in the context of theoretical controversies and try to assess its explanatory potential focusing on the integrity and dynamics of forms of life, their embeddedness into social practices and material contexts, and last but not least their causal efficaciousness.

Beyond coherence and fragmentation: The integrity and dynamics of life-forms Cultural analysis faces an important dilemma, between a coherent and a fragmented conception of culture (Swidler 2005: 181ff.; Kurakin 2019). It has been repeatedly claimed that any complex cultural pattern, whether it is called worldview, national culture, or style of life, is in fact bristling with inner contradictions. However, advocates of the ultimately fragmented and inconsistent character of cultural patterns are forced to adopt an agnostic epistemology and have to renounce the very possibility of cultural analysis. If culture really matters, we should be able to reconstruct the inner logics of cultural patterns. Facing the incoherence and inconsistency of cultures, the search for their deeper integrity should be seen as an epistemological imperative. Even though this postulate needs to be substantiated empirically, 
we think that a theoretical and methodological framework rendering this deeper integrity possible is a precondition for such empirical testing.

A similar claim can be made for life trajectories and their biographical descriptions. Despite contingencies and changes in life trajectories, the very notion of a biography or trajectory implies the unity of a life. Unsurprisingly, the denial to admit this unity leads to the rejection of the very concept of biography (e.g. Bourdieu 2004). Thus, biographies should always be analyzed as "wholes", as representation of a life as well as an expression of a specific form of life. This argument is well-represented in theories of the narrative identity (MacIntyre 1984; Ricoeur 1988; 1991), in which narrativity serves as a general paradigm of integration for personal as well as social identities. Critics of narrative identity theory have pointed out that narrativity is not the only mode of integration of a form of life (e.g. Strawson 2004; Tammi 2006). Galen Strawson, for example, distinguishes between Diachronics and Episodics as "two forms of life" which "differ significantly in their ethical and emotional form" (2004: 431), arguing that only for the former narrativity is important. While we find his general argument compelling, we would argue that episodes are narratively structured too, though they might not be integrated in a coherent large-scale biographical narrative.

We use the concept of "form of life" to describe how particular ways of living, as for example Diachronic and Episodic, are integrated - relatively independent from the viewpoints or accounts of actors. Reflexive narratives provided by actors are not the source of the integrity of a life-form, but merely one of its indicators. Biographical stories do not necessarily mirror the prereflexive form of life, rather - in structuralist terms - they are surface phenomena which need to be analyzed uncovering their deep cultural structure. For this reason, we prefer the analytical concept of form of life over narrower and more reflexive concepts such as narrative identity. Narrative analysis is only part of our methodological toolkit for analyzing forms of life, which will be elaborated later.

Wittgenstein introduced the concept of "form of life" to account for a cultural background, a deep meaning structure underlying practices and discourses: "human beings say that is true or false; and they agree in the language they use. That is not agreement in opinions but in form of life" (2009: 94, § 241). Behind the apparent differences in opinion there is a deep structure, embodied in shared practices, that makes understanding as well as disagreement possible. Partially, these deep structures can be described as binary codes that inform discourses and practices (cf. Alexander - Smith 1993; Luhmann 1995: 229ff.). The binary of truth and falsehood is such a deep structure which we share, even if we disagree about the truth of specific propositions. 
In Weber's Protestant Ethic (2001), the binary of salvation and damnation fulfills a similar function; it unifies a specific form of life while at the same time enabling different pathways to salvation. Early Protestant culture shared the concern for salvation; however, various denominations, forms of life in their own right, differed not only regarding their doctrines, but also in their practices of coping with the uncertainty of salvation. Thus, forms of life can be reconstructed and assembled at different levels of analysis, from large populations to smaller groups to individual cases.

There are various ways of being human, and every one of them is a more or less self-consistent, historically contingent unity - a form of life. That was a central point of the groundbreaking anthropological conceptions of the 20th century (e.g. Benedict 2005; Geertz 2006). Our approach has a close affinity with those theories and can be conceived as a continuation of their research practice. However, we go one step further in highlighting the discontinuities, inner contradictions and coping mechanisms as integral parts of a form of life as a dynamic cultural totality. A cultural analysis, which conceives biographies and cultures as meaningful wholes, should not ignore or eliminate internal contradictions, but recognize the power of tensions, which often drive personal as well as cultural change.

Robert K. Merton (1938) distinguished in his anomie scheme five ways of resolving the tension between cultural goals and institutionalized means (conformity, innovation, ritualism, retreatism and revolution), which served as useful heuristic for some of our cases. Following Merton, one of our respondents, Asya, a medical doctor in her mid-twenties, can be described as an innovator: She suffers from the tension between her ambitions and the institutional structure in the Russian medical field characterized by a slow career progress which she tries to overcome by innovative shortcuts, for example with a plan to found her own center of reproductive medicine. In the second interview, two years later, she partially retreats from her ambition arguing that in order to climb the institutionalized career ladder she would have to give up her femininity like some of the more experienced female doctors she met who "stopped being women", which she doesn't want: "A woman has to stay a woman". However, both strategies reference the interconnected symbols of motherhood and femininity, which are closely related for the respondent ("it is very important for a woman to be a mother").

According to Weber, the Calvinist form of life is characterized by the tension between predestination and the uncertainty of one's salvation. The Calvinist's innovative way of coping with this tension, the interpretation of inner-worldly success as a sign of salvation, led to religious practices that put "works" to the forefront. Furthermore, the secularization of the "protestant ethic" in the "spirit of capitalism" can be viewed as a continuation of the 
protestant form of life, as far as rationalization of life conduct is concerned. In this respect, we agree with Swidler's interpretation of Weber, that "what endures is the way action is organized" (1986: 276) - or what we call: form of life. Nevertheless, we think that Swidler's concept of culture as "repertoire" or "tool-kit" $(1986 ; 2005)$ is too loose to account for the unity and integrity of cultural patterns and biographies. Our in-depth case study will not only show how narratives of salvation enable actors to resolve biographical tensions and cope with uncertainty but also highlight the merits of our approach over Swidler's "tool-kit" theory.

Constellations: Contexts, autonomy and causality of life-forms

Cultural analysis, employing the binary of cultural vs. material factors, has to conceptualize the relation of action and meanings to their cultural (or "internal") and material/structural ("external") environments (cf. Alexander 1988). We think that Wittgenstein's form of life is apt to this challenge. According to Wittgenstein (2009), every statement is meaningful only in the context of a specific form of life. What is said and what is thought makes sense only in the context of a "grammar" (cf. Derra 2007: 33f.) - socially governed symbolic structures - as well as actual and potential actions, interactions, behavioral patterns and social institutions. This link between speech activities and forms of life is an important presupposition for the cultural analysis of biographies as a structural-hermeneutic reconstruction of life-forms, which tends to highlight the cultural elements, rather than the material or economic conditions of particular forms of life. Following the "strong program" in cultural sociology (Alexander - Smith 2001), we think that the analytical autonomy of culture is a crucial presupposition for any cultural analysis. The analytical autonomy of culture refers to the research strategy of bracketing-out material and social contexts in the first phase of the inquiry in order to isolate and reconstruct the inner logic of a form of life, its "grammar".

Still, we acknowledge that every form of life is embodied in social practices and embedded in an external environment, which includes material conditions, economic and institutional factors, spatial localization and social structure. According to Wittgenstein's famous argument (2009), the origins and functions of language can only be understood by acknowledging its entanglement with social practices and material objects. In the cultural analysis of biographies, Wittgenstein's bricks are replaced by the material and economic contexts of people's lives, their spatial localities and social positions. Together with cultural structures, they shape the wholeness of a form of life.

The external environment conditions but does not determine forms of life. This means that under the same material and economic conditions a plurality of forms of life can exist. Cultural meanings, social practices and material objects 
form "constellations" - to use Weber's term - whose features are more dependent on the composition than their distinct elements. Thus, the cultural analysis of biographies has to deal with constellations of the diverse elements, both internal and external, that shape forms of life. For the medical doctor and young mother Asya, breastfeeding is a complex of meanings (personal ambitions, ecological worldview) in a constellation with technologies (breast pumps) and material conditions (necessity to save money due to the low salaries of medical doctors in Russia, coordination of maternity with career).

Forms of life are causally efficacious. However, this efficaciousness should not be described in terms of a mechanical or intentional causality. Inspired by Wittgenstein's forms of life, Searle speaks of a "Background causality" (1995) through which a corporeal as well as cultural background enables specific intentions and actions. Similarly, Isaac Reed argues in his treatise on interpretation that "landscapes of meaning" exert a "forming causality", which shapes the intentions of actors and social mechanisms (2011). Forms of life operate in a similar way, not by forcing people to make certain choices, but by opening and limiting the horizon of possible choices as well as providing principles of choice.

The novelty of the forms of life approach becomes apparent in comparison with seemingly similar concepts such as "habitus" (Bourdieu, 1984). Bourdieu's habitus exhibits similar characteristics as our form of life: integrity and dynamism, embodiedness and embeddedness into social practices and contexts, and causal efficaciousness. Nevertheless, we concur with the cultural sociological critique by Alexander (1995: 136ff.), who argues that "habitus" is rather a material reflection than a cultural force. Bourdieu's habitus is too closely coupled to social structure to satisfy the criterion of "cultural autonomy". A form of life functions, like Bourdieu's habitus, as modus operandi of biographies without being - and this is the crucial difference - a pure function of social structure. Thus the concept allows accounting for the inner logic of biographies and the heterogeneity of life trajectories with the same social background.

\section{Towards a structural hermeneutics of life-forms - methodological tools}

In their manifesto for a "strong program" in cultural sociology, Alexander and Smith (2001) call for a "structural hermeneutics" which combines the analysis of deep meaning structures with a "thick description" a la Geertz. One problem with the "orthodox" strong program approach is, however, that it equates cultural depth with the binaries of structuralism. We argue instead that binaries are just one way to describe deep structures of meaning. Cultural structures can also take the form of master narratives and root metaphors, which are neither binaries nor surface phenomena. Structural hermeneutics, according to our 
understanding, is an interpretative methodology that tries to grasp meaning structures on basis of an interpretation of surface phenomena and explains the surface as a manifestation of deep structures. This structural-hermeneutic circle might seem futile at first, but it is in fact a fruitful spiral.

Our analysis of life-forms is inspired by the "documentary method", which stems from Karl Mannheim (1968/1923), but was further developed by Ralf Bohnsack and others (2010). In his seminal essay, Mannheim argued that social phenomena can be interpreted as "documents" or evidences of an underlying meaning structure. The documentary interpretation searches for "an identical, homologous pattern underlying a vast variety of totally different realizations of meaning" (1968/1923: 57). These different realizations are called "documents", the identical pattern "documentary meaning" - in contrast to the "objective meaning" established by social conventions and the "subjective meaning" referring to individual intentions. Aim of the documentary method is to capture the inner logic of "cultural wholes" - which we call forms of life 5 .

The documentary interpretation does not proceed by inductive generalization (cf. Mannheim 1968/1923: 57), but follows the logic of abduction. According to Peirce, abduction is a method of "studying the facts and devising a theory to explain them" (1998: 205). Recently, Timmermans and Tavory made a compelling case for "abductive reasoning" (2012) in qualitative research. Abductive reasoning in qualitative sociology is not heading straight for generalization, but begins its analysis with "surprising facts" and "empirical puzzles". A theory has to be found - in our case a specific form of life - that accounts for the facts and solves the puzzle posed by them. This is why the interpreter has to focus on contradictions and tensions, because their analysis is a key to the deeper integrity of the case. Thus, structural-hermeneutic interpretation uncovers a deep cultural structure accounting for a variety of facts - and particularly surprising facts. In the following we sketch a toolkit for the analysis of life-forms in narrative interviews, comprised of narratives, binaries and metaphors.

\section{Narratives}

The interpretation of narrative and biographical interviews is a well-established form of qualitative research (cf. Holstein - Gubrium 2011). According to Fritz Schütze, biographical narratives constitute "mediators between the objectivity and subjectivity of life stories" (1992: 196). We think that it is crucial to keep this tension and neither to reduce the biographical narrative to its objective core, the "story lived", nor to treat it as a purely subjective account, the "story

\footnotetext{
5 Our structural hermeneutics is primarily interested in the documentary method as a sociological reconstruction of the "atheoretical" meaning structure of what Mannheim calls "Weltanschauung" (1968/1923). For this reason, the ethnomethodological account of the documentary method as a mode of everyday theorizing and reasoning is of limited use for us (cf. Garfinkel 1967: 76-103).
} 
told". Similarly, the narratives offered by interviewees are always shaped by the interview situation and the interviewer, but their situatedness does negate the trans-situational logic of the form of life expressed in the narrative ${ }^{6}$.

The unity of a biographical narrative is not just superimposed arbitrarily by the researcher but shared - at least implicitly - by the storyteller. This fact is reflected in the notion of narrative identity (MacIntyre 1984; Ricoeur 1988, 1991), which is not confined to the act of storytelling, but affects the whole realm of human agency, which "is only characterized adequately when we know what the longer and longest-term intentions invoked are and how the shorter-term intentions are related to the longer" (MacIntyre 1984: 241). We do not want to suggest that each biography is necessarily structured by an allencompassing master narrative - this is essentially an empirical question - but would argue that even more episodic accounts are shaped by underlying narrative structures. Furthermore, narratives and narrative structures are often not known (e.g. as standard biographies or life scripts) by the actors who live them. Still, they can be sociologically reconstructed as crucial aspects of every form of life, structuring perceptions and actions as well as providing a sense of integrity and identity. In other words, we learn to live our lives and treat our lives as wholes from the narratives that surround us, although we are often not aware of them. Narratives shape biographies not primarily as "stories told" but as "stories lived".

Every society has its typical life trajectories as well as cultural canons of narratives and narrative genres - though one could argue that the conception of life as a trajectory as well as the genre of autobiography are typical for modern forms of life. In the analysis of biographical interviews, we can distinguish between different narrative patterns, for example narratives of upward or downward mobility. Cultural sociology, drawing on narrative theory and literary criticism, offers a variety of tools for the interpretation of narrative interviews, even though most relevant studies have focused almost entirely on the analysis of media discourses. Northrop Frye, particularly his theory of genres, was widely employed by discourse analysts (Wuthnow 1988; Smith 2005; Jacobs 1996) but can also be used to describe the structures of biographical narratives. Arguing with Weber against Weber, Alexander showed that the perception of new technologies is structured by narratives of salvation (2003). As we will show in our in-depth case study, narratives of salvation can also play important role in overcoming the inner tensions of biographies.

\footnotetext{
6 Our structural hermeneutics follows here the example of Ferdinand de Saussure, who conceived parole as a temporal, local and situational expression of a structural and trans-situational langue.
} 


\section{Binaries}

Forms of life revolve around symbolic binaries, which structure texts as well as practices on different levels. Symbolic binaries refer not only to words and their meanings, but also to different social spheres and life stages. In our interviews with adolescents, we found that biographical narratives and scenes are often framed by the binary childhood/adulthood. In our subsidiary sample containing "gifted" high school students, many respondents had a positive image of growing up and becoming an adult, whereas childhood was often associated with conformist and irresponsible behavior. However, there were also respondents that considered adulthood a "dubious honor" (Arnett 2004: 218f.), thus reversing the evaluation of the binary: "And actually, I don't want to grow up at all $[\ldots]$ when you're a kid, you can do whatever you want. And when you're adult, you have less time and opportunities for that" (Vera 15 years old). Here, adulthood is described as "boring" and conformist. Asya, our ambitious medical doctor, employs the same binary when she justifies her lifechoices as fulfillment of childhood dreams and expressions of her inner child. In her case, "authentic" adulthood is not the negation of childhood, but its fulfillment.

Gender, class or ethnic differences can play similar roles. Drawing on the strong program, we understand these differences between life spheres first of all as cultural codes that are used to draw symbolic boundaries, decoupled from "objective" social indicators (e.g. migrant background). In their analyses of young Turkish migrants in Germany, Bohnsack and Nohl (2002) highlighted the importance of the binary between an inner (family, ethnic community) and the outer sphere (German society) and distinguished four different styles of coping with this sphere difference, which constitute in our perspective different forms of Turkish adolescent life in Germany. In our interviews with respondents from a non-Russian ethnic background, we observed that ethnic boundaries played only a minor role and were re-described using the binary of city/countryside.

Another example, which is typical for our main sample, is the binary between "proper" and "improper" jobs. A "proper job" is not necessarily a "good job" (in terms of salary); it is not only interesting and meaningful, but first of all morally virtuous. Elena, an engineer working at an oil refinery, employs the binary of straight/evasive to distinguish between proper and improper jobs: "straight" refers to the production of real goods as honest work, whereas "management and sales" are not producing anything real but depend on the "cunning" of managers and salesmen. Such binaries distinguishing 
proper from improper jobs can also be found in interviews in other national contexts ${ }^{7}$.

\section{Metaphors}

We argue that metaphors play a crucial role in the analysis of life-forms, because they are more apt to grasp the pre-theoretical, experiential and practical understanding of actors (Lakoff - Johnson 2003; Kurakin 2014a). While interpreting interviews or other textual data, one can analyze metaphors not only as mere rhetorical devices but also as indicators of specific forms of life (focusing metaphors) or as structures constitutive of a form of life (root metaphors). Focusing metaphors are employed in the documentary method (Bohnsack et al. 2010), while the concept of root metaphor originates in the work of Stephen Pepper (1942).

According to Bohnsack, metaphors can often be found at the "culminating points" of group interviews and biographical narratives. These "focusing passages" or "focusing metaphors" are "much better qualified than others to identify the general pattern of orientation in the sense of the habitus of a group or a person" (2010: 104). Dilyara, a young mother from our subsidiary sample of young women, concludes a passage concerning the difficult process of merging of visions and building trust resulting in her marriage stating that her husband "leads the ship in the sea of life". This not only reflects a traditional gender view, where the wife "should guide a little and support her man", but also the conception of the family as a collective, as a "We" opposed to "I". Interestingly, she grew up in a dysfunctional family, with an unemployed and drinking father (whom she accuses of always using "I"). Thus, the metaphor of the "ship" reflects her collectivistic understanding and sacralization of family, which is constructed in contradistinction to her family of origin. Other respondents, such as the young doctor Asya, are in a similar situation (husband and child) but exhibit a more individualistic understanding of life.

In contrast to focusing metaphors, root metaphors organize experiences and meanings on a deeper level. We draw mainly on Lakoff's and Johnson's work (2003), which has not yet received enough attention in qualitative social research as well as in cultural sociology. The best empirical use of their metaphor theory is probably found in Lakoff's Moral Politics (2006), where he argues that American politics is shaped by the metaphor of the nation as family. $\mathrm{He}$ argues further that liberalism and conservatism constitute two different lifeforms, which are barely understandable for each other. According to Lakoff, a different understanding of family is reflected in a different conception of

\footnotetext{
7 Silva finds similar patterns in the United States juxtaposing the declining "iconic industrial working class" with the growing service sector (2013: 9-10). The poles of this binary are deeply embedded in material and social contexts of meaning-making: dignity, aesthetics and meaning of the respective forms of life are connected to economic stability/instability, rhythm and conditions of work (e.g. the role of trade unions).
} 
politics, which he uses to explain their political differences regarding different issues (taxation, abortion etc.). Similarly, we can look in interviews for root metaphors that explain a wide range of different statements and actions.

\section{Case study: Military life and the poetics of adaptation}

Due to their richness and openness, narrative interviews are one of the methods of choice for the analysis of life-forms. Their analysis aims to uncover cultural structures, most importantly narratives, binaries and metaphors, which are constitutive of their respective form of life. Having revealed those structures, special attention should be paid to the inner contradictions of each case and the respective coping strategies essential for the integrity of their form of life. According to our understanding, the analysis of life-forms has to be based on the interpretation and reconstruction of cases as wholes. For this reason, we will discuss in detail a case study from our main sample. The main reason for choosing this particular case lies in the fact that it exhibits the structures, elements and tensions which we discussed more salient than other cases. This might be due to the specificity of the military profession our respondent belongs to which seems to shape various aspects of life stronger than most other professions.

At the time of our first interview, Yegor was a 24-year-old man with military education who worked as a lecturer at a military university. Yegor was raised in a military family and chose to pursue a military career for himself. $\mathrm{He}$ married relatively early and had a child during his studies. However, he got divorced later and was at the time of the first interview in a new relationship. He still had the same job and the same girlfriend at the time of the second interview two years later. It is worth mentioning that his salary is comparatively high, especially in the context of the region (several times higher than average).

Yegor is self-confident man, with clear and precise judgments concerning life and career. His specialization and skills enable him not only to work for the army, but also in civil professions, for example as programmer. After the graduation, however, the army offered him, according to his own judgment, more stable and secure working conditions. In the first interview, he indulges in technicalities of his education and his job, exhibiting a high degree of professionalism and systematicity. In the second interview, he lectures in a similar way on the recent military reform in Russia. Nevertheless, he also stages himself as a kind of warrior-philosopher, quoting Goethe and contemplating about the secret of life and the universe. 


\section{Master binary: Military vs. civilian}

One of the first things that challenged our understanding of his form of life was a peculiar distribution of the uncertainties. On the one hand, he explicitly states that the uncertainty of the civil labor market was one of the reasons why he chose the military service. On the other hand, he kept repeating that life of a military man is full of uncertainty, and that a military man never fully belongs to himself:

A military man ... by his profession ... is every single minute ready for something.

Due to the changes of situation, due to moving, being on duty - poof, you go for a week, and arrive a month later. It happens very often, that today you're here, tomorrow you plan to go to the picnic, but this evening they call you and say:

"You're going [across the country] for 2 days". You take a plane to [that faraway place], but you can't go back - there's no other plane - and you stay there, without money, surviving somehow...

For Yegor, the form of life of a military man is characterized by a specific temporal uncertainty, often under harsh material conditions, subject to the military chain of command. Dominant in his autobiographical reflection is the distinction between military and civilian life. Despite the fact that the prominence of the binary was certainly provoked by the interview situation (with civilian interviewers), we believe that this binary is structurally grounded as we find similar patterns of meaning in other qualitative studies involving military men ${ }^{8}$. With civilian life being the constitutive "other" of military life, this binary transcends the immediate interview situation and pervades the life and thinking of Yegor. The binary military/civilian allows him to reflect on biographical choices in the past and develop visions for the future. In this particular case, the relation between the civil and the military sphere is quite complex. On the one hand, Yegor adamantly opposes the evaluation of specific life choices as better than others; on the other hand, he suggests that military life is superior in certain ways. Due to the virtues of military life, military men can be successful in the civilian life - but not the other way around:

This is why civilian organizations like to hire military men with experience.

Because he works on clean copy, he arranges things systematically. He never suddenly realizes that he forgot something; he never realizes that he didn't do something because he did everything and he didn't forget anything. He does everything pedantically, and there's nothing left hanging. [...] Military way gives this knowledge, it guides from the beginning. A man becomes more adaptive, better adjusted to future life, even to civilian one. Even when military men of age

\footnotetext{
8 Military life is usually evaluated against the background of a civilian career, and often with a similar distribution of uncertainties as in the case of Yegor: Silva, who interviewed several American military men in the course of her study, wrote that " $[t]$ he predictability and stability of military life-even in combat-allowed informants to gain a sense of control over their lives, often for the first time" (2013: 42). After five years of military service, "initially frightening but then surprisingly comforting in its routines", one of her respondents concluded: "I had some sort of sense of security in everything I did", (Silva 2013: 27). According to Silva, military service "appealed to young men and women as a beacon of security and choice in a storm of risk." (2013: 41).
} 
40 or 50 retire, they easily find themselves in civilian life. [...] Military service gives you initial stock for your life. Every man who was in army, even as draftee, he... his world outlook is changed; he becomes new man a little. He becomes more serious. Toward life, toward many things.

In a Hegelian way, one side of the distinction proves to be superior and more comprehensive, because it encompasses the other side. A key term used several times in the interview, expressing this specific superiority of the military life, is "adaptation". Like his father, who left the military to work for a company, he chose a "civilian specialization" that would allow him to be successful in civilian life too.

\section{Root metaphor: Adaptation}

Yegor does not only use "adaptation" to characterize the virtue of military men, but also to make sense of his divorce, which was allegedly caused by the inability of his ex-wife to adapt to the difficulties of a life with a military man ("many military men are divorced", "rare women can adapt to this"). In contrast, he celebrates his own mother's adaptability as her main virtue:

[...] my mom is a military woman, a wife of a military man. She understood it immediately. She was living for crumbs, she was eating frost-bitten potato, lived in the single room with the whole family, divided by folding screen, with two always screaming children, in dampness, humidity, unbearable conditions, from closed garrison she'd go out to sell things - with huge bags she was making frequent trips to Moscow, in order to support a family, while father was absent for days. It depends on the personality, on breeding, character, on how the reality is perceived.

Here the military/civil binary intersects with gender. There are not only military men, but also military women, whose main virtue consists in being able to adapt to the harsh life of military men. Already in the first, but more extensively in the second interview, Yegor applies the metaphor of adaptation to higher education, which teaches you "[h]ow to adjust and how to use your knowledge":

What is the difference between him and a man with no higher education? The difference is that educated man can take a book, read and learn things he did not know before. If education system works well, it produces not a man who knows something, but a man who can cope with everything.

We have seen that the adaptability of military (and educated) men is for Yegor the main indicator of their superiority. However, there is also a tension or even contradiction in his form of life, which we became only aware of once we discovered "The Secret".

\section{"The Secret": Puzzle, solution and narrative of salvation}

Towards the end of the interview, Yegor introduces a "hypothesis" of a responsive adaptive universe: "try to make your wishes real. You know, we form all 
material things with our emotions, views, intentions, it's just the same - strive for that and you will get that". Later, it turns out that this hypothesis is inspired by a tremendously successful Australian esoteric self-help movie (and book) called "The Secret" (2006). The movie offers classical self-help advice ("positive thinking") with an esoteric, cosmological and conspirational underpinning. "The Secret" is a guide to "wish-fulfillment", how to overcome the gap between the actual state and the desired state of affairs. It advocates a "magical voluntarism" (Gunn - Cloud 2010) claiming that objective reality is shaped by individual thoughts, feelings, and wishes. According to the Secret's "law of attraction", it's the consciousness that determines being - and not the other way around, as Marx famously argued. What attracts a seemingly downto-earth Russian military man to a foreign esoteric movie? From a methodological point of view, "The Secret" is a surprising fact, a puzzle. Employing abductive reasoning, we looked for an explanation and re-conceptualized the case structure, after which the initial puzzle appeared to be "a matter of course" (Peirce 1998: 231).

It is clear from the interview that the movie struck a chord in Yegor. Many examples that he initially gives to demonstrate his hypothesis are actually taken from the movie. This attraction is not accidental. Our interpretation showed that the ideology offered in the movie resonates within the life-form of the military men and answers to his present and pressing needs, which mainly concern the instability of his current life and a specific structural tension. This tension, or even contradiction, results from the contrast between his active life philosophy and self-confidence on the one hand and his rather passive role as a subject of adaptation on the other hand. Although adaption (much like Merton's "innovation") entails an active and creative component, it is ultimately passive and responsive with regard to the environment (unlike Merton's "revolution"). It is this crucial tension, between his activist self-image and the passivity of adaption, which is resolved by the narrative of salvation offered by "The Secret". From the perspective of the case, "The Secret" is not the puzzle, but a solution.

In Yegor's case, "The Secret" does not work as a recipe book for a successful life, but rather fulfills the function of a biodizee, an apology of life, similar to Leibniz's theodizee. In contrast to Leibniz's pre-stabilized harmony and Calvin's predestination, "The Secret" paints a dynamic picture of a universe responsive to one's needs. The fact that the supreme being of this cosmology, the universe, is characterized by adaptivity and responsiveness fits Yegor's world-view embracing flexibility and adaptivity as main virtues. This philosophy can be interpreted as activistic, "strive for that and you will get that", but - especially in the first interview - it is mostly portrayed in a rather passive way: "I'm going to do what you want, just make a wish". 
The prominent role of adaptability as virtue of military life and the conception of an adaptive universe makes it plausible to infer that adaption, deeply embedded in everyday practice, is the root metaphor constituting the structure of this case. "The Secret" allows Yegor not only to overcome the passivity of adaptation by means of adaptation, but also to cope with the past and colonize an uncertain future. This becomes clear in the following passage:

I did everything I did. That always was my motto, a little motto, a little credo, that

the future is in the hands of those who believe in the beauty of their dreams.

I believe in my dream, so, I believe in good that everything will change. Change

to the positive (smiling), and I don't regret.

The colonization of an uncertain future utilizing a salvation narrative inspired by "The Secret" becomes particularly salient in the following metaphor (which reappears, slightly modified, in the second interview): "It's like you're driving from [regional capital] to Moscow [in the night], your eyesight is 10 meters forward, lightened by headlights, but in the end you're in Moscow". In the end, the universe will have adapted to the confident believer.

\section{Form of life: Formula of integrity and discussion}

How can two contradictory and central motives like the self-understanding as an active self and the passivity of adaptivity coexist within one form of life? Yegor's solution to the puzzle involves a belief in the adaptivity of the universe: a virtuous man or woman has to adapt to life, but he or she also has dreams; and if he or she believes in those dreams, then the universe will adapt to those dreams". "The Secret" is used as a cultural tool that allows Yegor to overcome the tensions originating from the inner logics of his specific form of life.

Swidler (2005), whose interpretative strategy systematically disregards the coherence of culture, would at first glance come to seemingly similar conclusions. "The Secret" can be described as part of Yegor's "cultural repertoire" or "tool-kit". However, Swidler's theory has difficulties to explain why this particular tool is used and why Yegor is so attached to it. Only by taking the bigger picture of Yegor's life-form into account, we see that "The Secret" does not just fit to an isolated situation, but to his entire form of life. The attraction of the movie as well as his idiosyncratic appropriation of it becomes only understandable in the light of Yegor's specific form of life, his unsettled situation and the inherent strains of his worldview.

\footnotetext{
${ }^{9}$ One of the reviewers of this articles suggested, drawing on Yegor's education as a programmer, to characterize his form of life as "a programmer of his life (and perhaps the whole universe)". As intriguing as this interpretation might be, it is not really supported by the interview material, where "programming" is seldom referred to and not even implied as a root metaphor - in contrast to the ubiquitous "adaption" to the external realities beyond the immediate control of actors.
} 


\section{Conclusion}

We introduced the concept of form of life as a theoretical and methodological framework for the analysis of life trajectories and biographies. Its value for contemporary cultural sociology lies in the fact that forms of life allow to understand how cultural structures interact with social practices and their material conditions. Our endeavor thus goes in line with Durkheim's argument about the elementary forms of religious (and wider: social) life (1995/1912), arguably the foundational moment for cultural sociology. Durkheim's theory of ritual and the sacred links collective representations as cultural meanings to the actual practice in social interactions, which parallels Wittgenstein's idea of forms of life intertwining speech and thought with social practices.

Nevertheless, Durkheim's model was based on the study of "primitive" societies, which limits its applicability with regard to the more individualistic, fragmented and complex nature of contemporary societies. For this and other reasons, cultural sociologists have been developing Durkheim's ideas further, for example Alexander, who transposes Durkheimian rituals into social performances under the scrutiny of critics and audiences of modern media societies (2011). We are pursuing a similar goal, trying to explain the more complex forms of contemporary life examining how specific forms of commonsense shape everyday decisions and actions and how they are linked to typical ways of seeing the world.

The empirical illustrations we used in the paper and particularly our indepth case study aimed to shed light on the concept of life-form and its possible uses. Analyzing biographical narratives, one gets a complex picture of an actor's worldview and decisions, often containing contradictions and tensions. Instead of embracing the "incoherence of culture" (Pugh 2013: 54f.), our approach looks for the deeper integrity of cultural structures which resolve or even utilize tensions resulting from contradictory elements in life-styles, worldviews, and practices. Forms of life are structural wholes, which are shaped by their external contexts but also follow their own internal logic. In the case of Yegor, we observed a tension between desirable activeness and the rather passive virtue of adaptation, which is resolved by "the Secret" as a narrative of salvation. Similarly, Asya's innovative plan to found her own clinic as well as her later retreat to femininity provide solutions for the contradiction between her ambitions as a young medical doctor and the slow career-development in her field.

Well-established tools of cultural analysis, such as metaphors, binaries and narratives, make it possible to systematize the variety of meanings contained within biographies as distinguishable and analyzable cultural patterns. Nevertheless, it is the concept of form of life which ties these threads of 
meaning into the fabric of (social) life as a structural whole. While methodologically, cultural structures manifested in the interview text should first be analyzed in isolation of their immediate and extended context, they are later to be explained in their constellation with social and material contexts. In Yegor's case, the central motive of "adaptability" can only be adequately understood in the context of the specific uncertainties and demands of a military life. Forms of life are shaped by their cultural and material environment, but they nevertheless possess a causal efficacy of their own, structuring everyday practices and informing life choices.

So far, we have been primarily reconstructing forms of life at the level of individual cases. Despite our current focus on individual biographies, forms of life are not inherently individualistic. Cultural patterns informing people's lives have not been created by the individuals who employ them. Therefore in the future we plan to extend our approach to the analysis of typical biographies and life trajectories. In order to do this, the methodology needs to be refined further and clear procedures and criteria of delineating types have to be developed. Even though the forms of life behind typical trajectories do not have to coincide with the formal indicators, such as educational programs or professions, we believe that there are certain "existential" professions, such as medical doctors or military men, which harbor a very specific set of life-forms. As our next step, we would like to focus on one of those professions in the Russian context, describing the unity and diversity of its life-forms. We believe that the analysis of forms of life is a powerful and versatile approach, which can be applied in various local and national contexts and at different levels of analysis. In the light of contemporary research emphasizing the incoherence of biographies and culture (e.g. Swidler 2005, Pugh 2013), our analysis of forms of life is not only "innovative" but "revolutionary" (in the sense of Merton $1938)^{10}$. Not only do we introduce a new set of cultural sociological tools in the analysis of narrative interviews and biographies, we also redefine the goals of cultural analysis itself: Our aim is to identify and delineate different forms of life, understood as dynamic structural wholes consisting of cultural meanings embedded in social and material contexts.

Werner Binder is an assistant professor at the Masaryk University, Brno (Czech Republic). After studies in Mannheim, Potsdam and Berlin, he earned his PhD at the University of Konstanz with a thesis on the Abu Ghraib Scandal. He is author of Abu Ghraib und die Folgen (2013, Transcript), coauthor of Ungefähres (2014, Velbrück) and coeditor of Kippfiguren (2013, Velbrück).

${ }^{10}$ We are aware of the fact that some readers (e.g. postmodernists) might regard our endeavor as counterrevolutionary. 
His fields of interest are: Sociological theory, cultural sociology, textual and visual methods of interpretation.

Dmitry Kurakin is the Director of the Centre for Cultural Sociology and Anthropology of Education and a Leading Research Fellow at the Centre for Fundamental Sociology at the National Research University Higher School of Economics. He currently leads the Russian Panel Study "Trajectories in Education and Career". He is also a Faculty Fellow at the Yale Center for Cultural Sociology. He works in the fields of sociological theory, Durkheimian cultural sociology, focusing particularly on the theory of the sacred, cultural sociology of education and cultural sociology of the body.

Werner Binder ORCID iD https://orcid.org/0000-0001-8313-1353

Dmitry Kurakin ORCID iD https://orcid.org/0000-0002-7334-5953

\section{REFERENCES}

ALEXANDER, J. C., 1988: Action and Its Environments. In: Alexander, J. C.: Action and Its Environments. Toward a New Synthesis. New York: Columbia University Press, 301-333.

ALEXANDER, J. C., 1995: Fin De Siècle Social Theory. Relativism, Reduction, and the Problem of Reason. London; New York: Verso.

ALEXANDER, J. C., 2003: The Sacred and Profane Information Machine. In: Alexander, J. C.: The Meanings of Social Life. A Cultural Sociology. Oxford; New York: Oxford University Press, pp. 179-192.

ALEXANDER, J. C., 2011: Performance and Power. Cambridge: Polity.

ALEXANDER, J. C. - SMITH, P., 1993: The Discourse of American Civil Society. A New Proposal for Cultural Studies. Theory and Society 22 (2): 151-207.

ALEXANDER, J. C. - SMITH, P., 2001: The Strong Program in Cultural Theory. Elements of a Structural Hermeneutics. In: Turner, J. H. (ed.): Handbook of Sociological Theory. Wien; New York: Springer, pp. 135-150.

ARNETT, J. J., 2004: Emerging Adulthood. The Winding Road From the Late Teens Trough the Twenties. Oxford; New York: Oxford University Press.

BENEDICT, R., 2005: Patterns of Culture. New York: Mariner Books.

BOHNSACK, R., 2010: Documentary Method and Group Discussions. In: Bohnsack, R. - Pfaff, N. - Weller, W. (eds.): Qualitative Analysis and Documentary Method in International Educational Research. Opladen: Budrich, pp. 99-124.

BOHNSACK, R. - NOHL, A. M., 2002: Ethnisierung und Differenzerfahrung. Fremdheit als allägliches und als methodologisches Problem. ZBBS 2 (1): 15-36.

BOHNSACK, R. - PFAFF, N. - WELLER, W., 2010: Qualitative Analysis and Documentary Method in International Educational Research. Opladen: Budrich.

BOURDIEU, P., 1984: Distinction. A Social Critique of the Judgment of Taste. Cambridge: Harvard University Press.

BOURDIEU, P., 2004: The Biographical Illusion. In: Du Gay, P. - Evans, J. Redman, P. (eds.): Identity. A Reader. London: Sage, pp. 297-303. 
DERRA, A., 2007: Lebensform as a Wittgensteinian Way of Understanding Culture. Theoretical Perspectives for the (Intercultural) Dialogue. In: Kanzian, C. Runggaldier, E. (eds.): Cultures. Conflict - Analysis - Dialogue. Berlin: de Gruyter, pp. 33-42.

DURKHEIM, É., 1995/1912: The Elementary Forms of the Religious Life. New York: Free Press.

GARFINKEL, H., 1967: Studies in Ethnomethodology. Cambridge: Polity Press.

GEERTZ, C., 2006: The Interpretation of Cultures. Selected Essays. New York: Basic Books.

GUNN, J. - CLOUD, D. L., 2010: Agentic Orientation as Magical Voluntarism. Communication Theory 20 (1): 50-78.

HOLSTEIN, J. - GUBRIUM, J. F., 2011: Varieties of Narrative Analysis. London: Sage.

JACOBS, R. N., 1996: Civil Society and Crisis: Culture, Discourse, and the Rodney King Beating. American Journal of Sociology 101 (5): 1238-1272.

KURAKIN, D., 2014a: How Root Metaphors Structure Meaningful Life by Means of Emotions. Theory and Empirical Illustration from the Sphere of Academic Ethics. Center for Cultural Sociology at Yale Working Paper Series.

KURAKIN, D., 2014b: Russian Longitudinal Panel Study of Educational and Occupational Trajectories: Building Culturally-Sensitive Research Framework. Working Papers of Institute of Education.

KURAKIN, D., 2019: The Sacred, Profane, Pure, Impure, and Social Energization of Culture. In: The Oxford Handbook of Cognitive Sociology. Ed. by Wayne H. Brekhus and Gabe Ignatow. New York. Oxford University Press. Pp. 483-504.

LAKOFF, G., 2006: Moral Politics. How Liberals and Conservatives Think. Chicago: University of Chicago Press.

LAKOFF, G. - JOHNSON, M., 2003: Metaphors We Live By. Chicago: University of Chicago Press.

LUHMANN, N., 1995: Social Systems. Stanford: Stanford University Press.

MACINTYRE, A., 1984: After Virtue: A Study in Moral Theory. New York: University of Notre Dame Press.

MANNHEIM, K., 1968/1923: On the Interpretation of 'Weltanschauung'. In: Essays on the Sociology of Knowledge. London: Routledge, pp. 33-83.

MERTON, R. K., 1938: Social Structure and Anomie. American Sociological Review 3 (5): 672-682.

PEIRCE, C. S., 1998: Harvard Lectures on Pragmatism. In: The Essential Peirce. Selected Philosophical Writings (1893 - 1913). Bloomington: Indiana University Press, pp. 133-241.

PEPPER, S., 1942: World Hypotheses. Berkeley: University of California Press.

PUGH, A. J., 2013: What Good are Interviews for Thinking about Culture? Demystifying Interpretative Analysis. American Journal of Cultural Sociology 1 (1): 42-68.

PUGH, A. J., 2014: The Divining Rod of Talk. Emotions, Contradictions and the Limits of Research. American Journal of Cultural Sociology 2 (1): 159-163. 
REED, I., 2011: Interpretation and Social Knowledge. On the Use of Theory in the Human Sciences. Chicago: University of Chicago Press.

RICOEUR, P., 1988: Time and Narrative. Volume 3. Chicago; London: Chicago University Press.

RICOEUR, P., 1991: Narrative Identity. Philosophy Today 35 (1): 73-81.

SCHÜTZE, F., 1992: Pressure and Guilt. War Experiences of a Young German Soldier and Their Biographical Implications (Part 1). International Sociology 7 (2): 187208.

SEARLE, J. R., 1995: The Construction of Social Reality. London: Lane.

SILVA, J., 2013: Coming Up Short: Working-Class Adulthood in an Age of Uncertainty. Oxford University Press.

SMITH, P., 2005: Why War? The Cultural Logic of Iraq, the Gulf War, and Suez. Chicago: University of Chicago Press.

STRAWSON, G., 2004: Against Narrativity. Ratio 17 (4): 428-452.

SWIDLER, A., 1986: Culture in Action. Symbols and Strategies. American Sociological Review 51 (2): 273-286.

SWIDLER, A., 2005: Talk of Love. How Culture Matters. Chicago: University of Chicago Press.

TAMMI, P., 2006: Against Narrative ("A Boring Story")". Partial Answers: Journal of Literature and the History of Ideas 4 (2), 19-40.

TIMMERMANS, S. - TAVORY, I., 2012: Theory Construction in Qualitative Research From Grounded Theory to Abductive Analysis. Sociological Theory 30 (3): 167-186.

VAISEY, S., 2014: Is Interviewing Compatible with the Dual-process Model of Culture? American Journal of Cultural Sociology 2 (1): 150-158.

WEBER, M., 2001: The Protestant Ethic and the Spirit of Capitalism. London; New York: Routledge.

WILLIAMS, R., 1960: Culture and Society. 1780-1950. New York: Anchor Books.

WITTGENSTEIN, L., 2009: Philosophische Untersuchungen. Philosophical Investigations, Malden; Oxford: Blackwell.

WUTHNOW, R., 1988: Religious Discourse as Public Rhetoric. In: Communication Research 15 (3): 318-338. 